\title{
Pendampingan Suami pada Ibu Bersalin Berhubungan dengan Keberhasilan Inisiasi Menyusu Dini
}

\author{
Fitriana \\ Sekolah Tinggi IImu Kesehatan Guna Bangsa \\ JI. Ringroad Utara, Condongcatur, Kec. Depok, Kabupaten Sleman, Daerah Istimewa Yogyakarta 55283, Indonesia \\ Email: fitri2310@ymail.com
}

\begin{abstract}
Abstrak
Program Inisiasi Menyusu Dini sangat diperlukan untuk bayi yang baru lahir untuk mencegah tingginya kematian neonatal. Inisiasi Menyusu Dini (IMD) adalah pencarian puting susu ibu segera setelah bayi lahir. Penelitian ini bertujuan untuk menganalisis hubungan antara pendampingan suami pada ibu bersalin dengan keberhasilan inisiasi menyusu dini. Penelitian ini menggunakan metode kuantitatif, penelitian observasional analitik dengan desain cross sectional. Teknik pengambilan sampel menggunakan total sampling. Sampel dalam penelitian ini sebanyak 39 perempuan melahirkan di bidan praktek mandiri (BPM) Kecamatan Depok Kabupaten Sleman, sedangkan alat pengumpulan data menggunakan kuesioner dan lembar observasi. Teknik analisis data regresi logistik hubungan pendampingan suami dengan keberhasilan Inisiasi Menyusu Dini $(O R=3,46 ; C / 95 \%=1,44-6,00 ; p=0,014)$. Ada hubungan yang signifikan antara pendampingan suami pada ibu bersalin dengan keberhasilan Inisiasi Menyusu Dini di Kecamatan Depok Kabupaten Sleman. Pendampingan suami pada ibu bersalin akan meningkatkan keberhasilan ibu bersalin untuk menyusui bayinya sedini mungkin.
\end{abstract}

Kata Kunci: pendampingan suami, inisiasi menyusu dini

\section{Husband Assistance in Maternity was Related to the Success of Early Initiation of Breastfeeding}

\begin{abstract}
Early Initiation of Breastfeeding is important for newborns to prevent high neonatal mortality. Early Initiation of Breastfeeding Is where a baby searchs for Mother's nipple immediately after birth. This study aimed to analyze the The relationship between husband assistance in maternity and the success of early initiation of breastfeeding. This study Is a quantitative research, analytical observational study with cross sectional design. The sampling technique used total sampling. Sample were a total of 39 women whose delivery in private midwife clinics. DepokSleman while The data collection used questionnaireand observation sheets The result from logistic regression showed that husband assistancewas significantly associated with early initiation of breastfeeding (OR=3.46; $C / 95 \%=1.44$ to $6.00 ; P=0.014)$ husband assistance on maternity womenmay increase the success of maternity womento breastfeed their babies as early as possible.
\end{abstract}

Keywords: breastfeeding, early initiation of breatsfeeding, husband assistance, maternity

Info Artikel:

Artikel dikirim pada 31 Maret 2017

Artikel direvisi pada 28 Agustus 2017

Artikel diterima pada 27 September 2017

DOI: http://dx.doi.org/10.21927/jnki.2017.5(2).139-143 


\section{PENDAHULUAN}

Kesehatan Ibu dan Anak, merupakan sebuah isu yang tidak pernah lekang oleh waktu, karena kesehatan ibu dan anak tidak dapat terlepas dari Indikator Human Development Index (HDI). Di Indonesia salah satu indicator keberhasilan pembangunan kesehatan adalah cakupan pemberian ASInya. UNICEF melakukan survey terhadap 1.677 bayi di Indonesia. Mengungkap keterkaitan antara asupan ASI dengan Infeksi Saluran Pernapasan Akut (ISPA) dan diare pada bayi sebagai penyebab AKB. Salah satu langkah dalam mensukseskan pemberian ASI eksklusif adalah dengan cara melakukan inisiasi menyusu dini (1).

Faktor penyebab utama kematian bayi di Indonesia adalah kematian neonatal sebesar $46,2 \%$, diare sebesar $15,0 \%$, dan pneumonia sebesar $12,7 \%$. Berdasarkan hal tersebut, diperlukan langkah-langkah nyata dalam upaya pencegahan kasus-kasus yang menyebabkan tingginya angka kematian bayi, khususnya angka kematian neonatal. Faktor penyebab kematian neonatal diakibatkan infeksi $36 \%$, prematuritas $28 \%$, dan asfiksia $23 \%$. Salah satu cara yang dapat dilakukan untuk meningkatkan kekebalan tubuh neonatal yaitu memberikan kolostrum sesegera mungkin kepada bayi baru lahir yang mengandung immunoglobulin $\mathrm{A}(\lg \mathrm{A})$ yang membantu melapisi usus bayi yang masih rentan dan mencegah kuman memasuki usus bayi (2).

Program inisiasi menyusu dini (IMD) sangat perlu dilakukan kepada bayi yang baru lahir untuk mencegah tingginya kematian neonatal. IMD adalah perilaku pencarian puting payudara ibu sesaat setelah bayi lahir. Pada IMD, bayilah yang diharapkan berusaha untuk menyusu. Pada jam pertarma, bayi berhasil menemukan payudara ibunya. Inilah awal hubungan menyusui antara bayi dan ibunya, yang akhirnya berkelanjutan dalam kehidupan ibu dan bayi (3).

Hubungan IMD danASI eksklusif telah dibuktikan melalui beberapa penelitian, antara lain dilaporkan bahwa IMD dapat menurunkan kematian bayi sebesar $22 \%$ pada 28 hari pertama kehidupan. Berpengaruh terhadap durasi menyusui, perilaku ibu dan fungsi fisiologis bayi, memberikan peluang delapan kali lebih besar untuk keberhasilan pemberian ASI eksklusif, dan memberikan mental positif bagi ibu yaitu terjalin ikatan kuat dengan bayi dan perasaan nyaman untuk menyusui (4).

Cakupan inisiasi menyusu dini (IMD) di Indonesia masih rendah. Hasil Riskesdas tahun 2013 hanya $34,5 \%$ bayi yang menyusu kurang dari satu jam setelah persalinan (5). Menurut data UNICEF tahun 2009, menyebutkan bahwa angka cakupan praktik IMD di Indonesia dari tahun 2003 hingga 2008 sebesar $39 \%$ dan cakupan ASI eksklusif 6 bulan sebesar $40 \%$ perlu dilakukan upaya-upaya secara komprehensif untuk meningkatkan cakupan IMD (4).

Prasetyono menyatakan bahwa dalam proses IMD dibutuhkan kesiapan mental ibu (3). Ibu tidak perlu merasa terganggu dengan adanya bayi yang diletakkan di atas perutnya. Saat inilah pendampingan suami dan keluarga sangat dibutuhkan oleh seorang ibu setelah melahirkan untuk melakukan IMD. Beberapa tindakan perhatian yang dapat dilakukan suami seperti mengungkapkan kata-kata sebagai penenang hati ibu dan ucapan penuh kasih sayang.

Selain pendampingan dari keluarga khususnya suami, maka dukungan dari petugas kesehatan juga mendukung pelaksanaan IMD. Hal ini dikarenakan tenaga kesehatan berperan menangani langsung proses persalinan ibu, dan ibu tidak dapat melakukan IMD tanpa dukungan dan fasilitas dari tenaga kesehatan. Pendidikan dan konseling yang memadai yang diberikan oleh petugas kesehatan diperlukan untuk memperbaiki praktik eksklusif menyusui dengan meningkatkan inisiasi menyusui tepat waktu dalam waktu 1 jam setelah parturisi, seperti bisa dilakukan dengan memberikan konseling mencakup diskusi tentang manfaat pemberian ASI secara eksklusif, menjelaskan dan memperagakan prosedur yang benar untuk menyusui, dan diskusi tentang diet yang cocok untuk menyusui ibu (6). Namun pada kenyataannya, sering ditemui penolong persalinan memisahkan bayi dan ibunya segera setelah lahir, untuk dibersihkan, ditimbang, ditandai, dan diberi pakaian. Hal ini menyebabkan inisiasi menyusu dini tidak dilakukan (7).

Tujuan dari penelitian ini adalah untuk menganalisis hubungan antara pendampingan suami pada ibu bersalin dengan keberhasilan inisiasi menyusu dini.

\section{BAHAN DAN METODE}

Penelitian ini termasuk jenis penelitian kuantitatif, dengan metode penelitian observasi analitik, dan menggunakan desain cross sectional, dimana hubungan antara faktor-faktor risiko dan dampak atau efeknya diobservasi pada waktu yang sama. Penelitian ini dilaksanakan pada bulan April sampai bulan Juni 2015 di Bidan Praktik Swasta Kecamatan Depok Kabupaten Sleman. Sampel diambil dari semua 
ibu hamil yang melakukan pemeriksaan kehamilan di tempat bidan tersebut. Menurut Sugiyono, teknik pengambilan sampel dalam penelitian ini adalah total sampling, yaitu semua anggota populasi digunakan sebagai sampel penelitian (8), sehingga jumlah sampel dalam penelitian ini adalah semua ibu bersalin yang melahirkan di tempat bidan praktik swasta tersebut pada bulan April sampai bulan Juni 2015. Alat untuk mengumpulkan data tersebut berupa kuesioner tertutup (closed ended) lembar observasi (checklist) dan Instrumen yang dipergunakan adalah kuesioner pendampingan suami yang pernah digunakan oleh Nurjannah yang telah di uji validitas dan reliabilitas di RS PKU Muhammadiyah Bantul sehingga kuesioner ini dinyatakan shahih dan layak sebagai instrumen penelitian (9), sedangkan lembar observasi (checklist) Inisiasi Menyusu Dini disadur dari lembar observasi JNPK-KR Depkes RI tahun 2008 (10).

Metode pengumpulan data dalam penelitian ini adalah dengan cara menyebar kuesioner kepada ibu bersalin sebagai responden kemudian meminta menuliskan jawaban pada lembar yang telah tersedia sesuai dengan petunjuk dalam kuesioner tersebut. Sebelum mengisi kuesioner responden diminta mengisi lembar informed consent menjadi responden dan menandatanganinya. Pengambilan data dilakukan oleh peneliti yang sebelumnya peneliti memberikan penjelasan-penjelasan tentang pengisian kuesioner. Untuk menentukan hubungan dan uji hipotesis antara 2 variabel Antara pendampingan suami dan keberhasilan Inisiai Menyusu Dini (IMD) dengan menggunakan metode uji chi-square dan analisis multivariat dengan regresi logistik.

\section{HASIL DAN BAHASAN}

Setelah dilakukan observasi diketahui sebanyak 29 ibu bersalin didampingi oleh suaminya dan $10 \mathrm{ibu}$ bersalin tidak didampingi oleh suaminya.

Tabel 1. Data Kategorik Subjek Penelitian

\begin{tabular}{lll}
\hline Variabel & $\mathbf{n}$ & \% \\
\hline Pendampingan Suami & & \\
Didampingi & 29 & 74,4 \\
Tidak Didampingi & 10 & 25,6 \\
Jumlah & 39 & 100 \\
\hline
\end{tabular}

Sumber: Data Primer Tahun 2015

Berdasakan Tabel 1 menunjukkan hasil bahwa ibu bersalin mayoritas di dampingi oleh suaminya
$(74,4 \%)$ di samping ibu selama proses persalinan dengan membatu memilih posisi yang nyaman, mengelus punggung ibu dan mengusap keringat ibu, serta memegang tangan ibu.

Mira menjelaskan, bahwa dukungan suami merupakan salah satu sumber dukungan dari keluarga yang sangat ampuh manfaatnya, karena dapat memberikan dampak yang positif bagi ibu melahirkan dan menyusui (11). Salah satu peran suami yang paling bermanfaat adalah menciptakan suasana yang menyenangkan. Menyenangkan disini adalah keadaan dimana seorang istri merasa nyaman, aman karena merasa terlindungi dan bahagia karena ibu merasa mendapatkan dukungan serta kasih sayang dari suami.

Menurut Aprilia, ibu bersalin yang merasa nyaman dan bahagia akan melakukan hal-hal positif untuk dirinya dan anaknya dengan penuh keikhlasan dan kesungguhan, maka dari itu peran keluarga dalam pendampingan ibu selama bersalin sangat diperlukan untuk pemulihan dan keadaan psikologi ibu bersalin (12). Dashti juga menyatakan bahwa peran suami dalam mendampingi ibu bersalin sangatlah besar, karena informasi serta dukungan yang diberikan suami kepada ibu bersalin memberikan semangat yang luar biasa untuk merawat bayi yang baru saja dilahirkanya (13).

Tabel 2. Tabulasi Silang antara Variabel Dependen dan Independen

\begin{tabular}{lcccc}
\hline \multirow{2}{*}{ Variabel } & \multicolumn{2}{c}{ IMD (\%) } & \multirow{2}{*}{ OR } & $\boldsymbol{p}$ \\
\cline { 2 - 3 } & Berhasil & Tidak & & \\
\hline Pendampingan Suami & & & & \\
Ya & 71,8 & 74,4 & 15,9 & $<0,0001$ \\
Tidak & 2,6 & 25,6 & & \\
\hline
\end{tabular}

Sumber: Data Primer Tahun 2015

Berdasarkan Tabel 2 menunjukkan hasil bahwa ibu bersalin yang di dampingi oleh suaminya mempunyai kemungkinan 15,9 kali lebih besar daripada ibu bersalin yang tidak di dampingi oleh suaminya. Peran suami dalam memberikan dukungan kepada ibu bersalin sangatlah besar karena ini akan memengaruhi halhal positif yang akan dilakukan ibu terutama terhadap bayinya. Hal ini sesuai dengan penelitian Suryani dan Mularsih, tentang adanya pengaruh yang besar pendampingan suami terhadap istri yang sedang melahirkan untuk melakukan hal-hal positif seperti Inisiasi Menyusu Dini (IMD) serta perawatan terhadap bayi yang baru saja dilahirkan (14). 
Keberhasilan IMD dipengaruhi oleh beberapa faktor, satu diantaranya adalah peran petugas kesehatan yang berperan besar dalam proses persalinanya, budaya dan dukungan keluarga terutama suami. Seperti yang dinyatakan oleh hasil penelitian Setegn, konseling pasca kelahiran pada pemberian ASI dikaitkan secara signifikan dengan inisiasi menyusui yang tepat waktu (15). Hasil penelitian Widiastuti, menyatakan bahwa variabel yang paling berkontribusi dalam keberhasilan IMD adalah dukungan keluarga terutama suami (16). Hasil penelitian ini sejalan dengan hasil penelitian Hidayat dan Dewantiningrum yang juga menyatakan bahwa variabel yang paling berkontribusi dalam keberhasilan IMD adalah dukungan keluarga (17).

Menurut Roesli, Inisiasi Menyusu Dini (IMD) sangat berperan dalam keberlanjutan ibu dalam pemberian ASI eksklusif pada bayi yang dilahirkanya. Oleh sebab itu Roesli sangat menganjurkan kepada ibu bersalin untuk segera memberikan ASInya kepada bayi baru lahir (18).

Tabel 3. Analisis Regresi Logistik

\begin{tabular}{|c|c|c|c|c|}
\hline \multirow[b]{2}{*}{ Variabel } & \multicolumn{2}{|c|}{$\mathrm{Cl} 95 \%$} & \multirow[b]{2}{*}{ OR } & \multirow[b]{2}{*}{$p$} \\
\hline & $\begin{array}{c}\text { Batas } \\
\text { Bawah }\end{array}$ & $\begin{array}{c}\text { Batas } \\
\text { Atas }\end{array}$ & & \\
\hline Pendampingan Suami & 1,44 & 6,00 & 3,5 & 0,001 \\
\hline
\end{tabular}

Sumber: Data Primer Tahun 2015

Berdasarkan Tabel 3 menunjukkan hubungan positif dan secara statistik signifikan antara pendampingan suami pada ibu bersalin dengan keberhasilan inisiasi menyusu dini. Ibu yang didampingi oleh suaminya memiliki kemungkinan 3,5 kali lebih besar dari pada ibu yang tidak didampingi oleh suaminya (OR=3,5; $\mathrm{Cl} 95 \%$ $1,44$ hingga 6,$00 ; p=0,0014)$. Artinya semakin tinggi pendampingan suami pada ibu bersalin maka semakin tinggi tingkat keberhasilan inisiasi menyusu dini secara statistik signifikan. Kehadiran seorang suami dalam proses persalinan akan memberikan dampak yang sangat luar biasa terutama bagi psikologi ibu. Ibu akan merasakan tenang dan nyaman sehingga dalam proses dan setelah persalinanpun ibu akan dengan senang hati melakukan hal-hal yang seharusnya ibu lakukan. Hal ini sesuai dengan hasil penelitian Mukhoirotin yang menyatakan, bahwa pendampingan suami pada ibu bersalin secara terus menerus akan memberikan dampak yang sangat positif karena ibu merasa mendapatkan dukungan emosional sehingga ibu akan merasa berkurangnya rasa sakit dan bersemangat untuk melakukan hal-hal yang semestinya dilakukan ibu pasca bersalin (19).

Mannion juga menyatakan bahwa ibu merasa lebih cakap dan percaya diri tentang menyusui saat mereka melihat pasangannya mendukung dengan dorongan verbal dan keterlibatan aktif dalam kegiatan menyusui (20). Pada penelitian lainya disebutkan bahwa terdapat beberapa studi observasional yang menyatakan bahwa suami merupakan salah satu aspek yang dapat memengaruhi produksi ASI terkait faktor psikologi ibu (21). Hal ini sejalan dengan pendapat Paramashanti yang menyatakan bahwa dukungan keluarga dan tingkat pendidikan suami yang tinggi juga sangat penting dalam memungkinkan ibu mempraktikkan pemberian ASI secara eksklusif (22).

\section{SIMPULAN DAN SARAN}

Berdasarkan hasil analisis hubungan dari variabel pendampingan suami dengan keberhasilan Inisiasi Menyusu Dini (IMD) dapat diambil kesimpulan bahwa ada hubungan pendampingan suami dengan keberhasilan Inisiasi Menyusu Dini (IMD), hal ini menjelaskan tingginya kontribusi dari pendampingan suami dengan tindakan ibu dalam melakukan inisiasi menyusu dini. Sehubungan dengan hal ini suami sebaiknya mendampingi istri pada saat persalinan, memberikan perhatian dan menunjukkan kasih sayang sehingga ibu bersalin merasa nyaman dan bahagia pada saat persalinanya serta berdampak positif juga pada kesehatan dan penerimaan sang ibu terhadap bayinya setelah melahirkan. Baiknya pendampingan suami akan meningkatkan keberhasilan para ibu bersalin dalam Inisiasi Menyusu Dini (IMD), yang berarti bayi berhasil menemukan payudara ibunya pada saat setelah melahirkan. Karena keberhasilan inisiasi menyusu dini ini akan memberikan beberapa keuntungan baik untuk bayi dan ibu, seperti membantu bayi tetap hangat dan dimungkinkan memiliki peran dalam meningkatkan perkembangan sistem saraf bayi, untuk melakukan hal-hal seperti itu ibu bersalin membutuhkan dukungan dan semangat dari orangorang terdekat seperti suami dan keluarga yang lain.

\section{RUJUKAN}

1. Dinas Kesehatan DIY. Profil Kesehatan Daerah Istimewa Yogyakarta Tahun 2012. Yogyakarta: Dinas Kesehatan DIY; 2013. 
2. Sejatiningsih S, Raksanagara AS. Program inisiasi menyusu dini dalam rangka menurunkan angka kematian neonatal. J Pustaka UNPAD [Internet]. 2009;1-10. Available from: http://pustaka.unpad. ac.id/wp-content/uploads/2013/02/Pustaka_ unpad_Inisiasi_Menyusu_Dinipdf.pdf

3. Prasetyono D. Buku Pintar ASI Eksklusif: Pengenalan, Praktik, dan Kemanfaatankemanfaatannya. Yogyakarta: Diva Press; 2012.

4. Noer E, Muis S, Aruben R. Praktik Inisiasi Menyusu Dini dan Pemberian ASI Eksklusif Studi Kualitatif pada Dua Puskesmas, Kota Semarang. Media Med Indones. 2011;45(3):144-50.

5. Riset Kesehatan Dasar. Badan Penelitian dan Pengembangan Kesehatan Kementerian RI tahun 2013 [Internet]. 2013 [cited 2014 Jan 1]. Available from: http://www.depkes.go.id/ resources/download/general/Hasil.Riskesdas. 2013.pdf

6. Paramashanti BA, Hadi H, Made I, Alit G. Timely initiation of breastfeeding is associated with the practice of exclusive breastfeeding in Indonesia. Asia Pac J Clin Nutr [Internet]. 2016 [cited 2017 Sep 27];25:52-6. Available from: http://apjcn.nhri. org.tw/server/APJCN/25 Suppl 1/S52.pdf

7. UNICEF. Initiation Of Breastfeeding By Breast Cawl. India; 2007.

8. Sugiyono. No Statistika untuk Penelitian. Bandung: Alfabeta; 2010.

9. Nurjannah S. Hubungan Dukungan Suami Dengan Pelaksanaan Inisiasi Menyusu Dini [Internet]. 2014 [cited 2015 Jan 1]. Available from: http://opac.unisayogya.ac.id/461/1/NASKAH PUBLIKASI.pdf

10. JNPK-KR Depkes RI. Pelatihan Klinik Asuhan Persalinan Normal. Jakarta: Departemen Kesehatan RI; 2008.

11. Mira YI, Arneliawati. Hubungan Dukungan Suami Terhadap Motivasi Ibu Memberi ASI Pada Bayi 0-6 bulan di wilayah Kerja Puskesmas Rakit Kulim Kabupaten Indragiri Hulu. Universitas Riau; 2013.

12. Aprillia Y. Analisis Sosialisasi Program Inisiasi Menyusu Dini dan ASI Eksklusif Kepada Bidan di Kabupaten Klaten [Internet]. Universitas Diponegoro Semarang; 2009. Available from: http://eprints.undip.ac.id
13. Dashti M, Scott JA, Edwards CA, Al-Sughayer M. Determinants of Breastfeeding Initiation among Mothers in Kuwait. Int Breastfeed J [Internet]. 2010 Jul 28 [cited 2013 Jan 23];5:7. Available from: http://www.ncbi.nlm.nih.gov/pubmed/20667112

14. Suryani D, Mularsih S. Hubungan Dukungan Suami dengan Pelaksanaan Inisiasi Menyusui Dini Pada Ibu Post Partum di BPS Kota Semarang. J Din Kebidanan. 2011;1(1):1-15.

15. Setegn T, Gerbaba M, Belachew T. Determinants of Timely Initiation of Breastfeeding among Mothers in Goba Woreda, South East Ethiopia: a cross sectional study. BMC Public Health [Internet]. 2011 Apr 8;11:217. Available from: http://www.ncbi.nlm.nih.gov/pubmed/21473791

16. Widiastuti $Y$, Rejeki S, Khamidah N. No Title. J Keperawatan Matern. 2013;1(2):142-6.

17. Hidayat KA, Dewantiningrum J. Perbandingan Pelaksanaan Inisiasi Menyusu Dini Berdasar Tingkat Pengetahuan Ibu Hamil. Media Med Muda [Internet]. 2012 [cited 2017 Sep 14];1(1). Available from: http://id.portalgaruda.org/?ref=browse\&mo $\mathrm{d}=$ viewarticle\&article $=73710$

18. Roesli U. Inisiasi Menyusui Dini plus ASI Eksklusif. Jakarta: Pustaka Bunda; 2008.

19. Mukhoirotin K. Pengaruh Pendampingan suami Terhadap Kecemasa Ibu Pada Proses Persalinan Kalla I (Fase Laten Fase Aktif) [Internet]. 2010 [cited 2015 Jan 1]. Available from: www.journal. unipdu.ac.id

20. Mannion CA, Hobbs AJ, McDonald SW, Tough SC. Maternal Perceptions of Partner Support during Breastfeeding. Int Breastfeed J [Internet]. 2013;8(1):4. Available from: http:// internationalbreastfeedingjournal.biomedcentral. com/articles/10.1186/1746-4358-8-4

21. Rahayu RY, Sudarmiati S. Pengetahuan Ibu Primipara tentang Faktor-Faktor yang dapat Mempengaruhi Produksi ASI [Internet]. 2012 [cited 2014 Nov 15]. Available from: http://xn-ejournals1-vu6e.undip.ac.id/index.php/inursing

22. Ratnasari D, Paramashanti BA, Hadi $H$, Yugistyowati A, Astiti D, Nurhayati E. Family support and exclusive breastfeeding among Yogyakarta mothers in employment. Asia Pac J Clin Nutr [Internet]. 2017 [cited 2017 Sep 27];26:31-5. Available from: http://apjcn.nhri.org. tw/server/APJCN/26/Suppl 1/S31.pdf 